\title{
To Teach Or Not To Teach Astronomy, That Is The Question: Results Of A Survey Of Québec's Elementary Teachers
}

\author{
Pierre Chastenay, Université du Québec à Montréal, Canada
}

\begin{abstract}
To determine the extent of astronomy teaching in Quebec's schools, we conducted an online survey of 500 Québec's elementary (K-6) teachers between January and March 2015. With a 35-items questionnaire, we wanted to find out how these elementary teachers teach astronomy (or not) to their classrooms, what is their background in Science \& Technology (S\&T), what pre-service education they received, the reasons why they teach astronomy or not to their students, the resources and materials they have at their disposal, their perception of the effectiveness of pre-and inservice training they received, and their perceived needs for in-service training. Results show that the majority of teachers surveyed didn't study science beyond high school and have had no experience in S\&T employment before becoming a teacher. We also found that only half of the teachers surveyed actually teach astronomy to their class, mostly by using reading and writing material, and that 39\% of "Astronomy teachers" in our sample teach astronomy to their class between 6 and 10 hours per year. Major hurdles to astronomy teaching perceived by the teachers in our survey are a lack of experience and training in astronomy, a lack of resources and equipment, inadequate classroom arrangement, and their own, self-perceived incompetence in astronomy. Pre-service education in astronomy, in science and in science teaching is also considered mainly unsatisfactory, or non-existent in the case of astronomy; in-service training in astronomy is mainly composed of conversations with colleagues. Most respondents thus consider in-service training in astronomy to be inefficient or inexistent.
\end{abstract}

Keywords: Astronomy Education; Teacher Education; Elementary

1

n 2006 and 2007, Québec's Ministry of Education introduced astronomy teaching as an integral part of the province's elementary (grades K-6) and secondary (grades 8-12) schools curricula (Ministère de l'Éducation, du Loisir et du Sport [MÉLS], 2007; Ministère de l'Éducation du Québec [MÉQ], 2006a, 2006b). Before that, only a few astronomical topics were taught in the secondary 1 (grade 8) Geography course, namely the place of Earth in space, Earth's diurnal motion, phases of the Moon and the seasons (Thouin, 2015). The introduction of astronomy in the curriculum, although not as a mandatory topic at the elementary school level (in Québec, astronomy teaching is mandatory only at the secondary level of instruction), has created a situation in which in-service teachers were asked to teach a subject for which they had received little or no training at all. Now, more than a decade later, we ask how is astronomy taught in Québec's elementary schools?

To answer this question, we created a 35-question, online anonymous survey that probed in-service elementary school teachers about the way they teach astronomy, the topics they covered, their aims and goals in teaching astronomy, the materials they used, their pre-service as well as in-service training in science and in astronomy, the limitations and problems they encounter in teaching astronomy, and the reasons some of them decide not to teach astronomy at all to their students. It is these research questions that guided the development of the survey questionnaire.

A preliminary version of the survey instrument (described below) was first used in a pilot study in December 2013 during an elementary teachers' professional development meeting (Congress 2013 of the Association québécoise des enseignantes et des enseignants $d u$ primaire, AQEP, held Dec. 12-13 in Québec City, Québec) where 138 respondents used an iPod to answer the survey questions (see Chastenay (2014) for results of this pilot study); a slightly modified version of the instrument was used online from January to March 2015, when elementary teachers 
from all over Québec were invited to complete the survey $(\mathrm{N}=500)$. Results from this second study will be presented here.

In this paper, we will first review similar surveys of teachers that were conducted in Canada and in the United States in previous years, to compare with our own results. We will then describe our questionnaire and the conditions of its application, and then present our major findings. In conclusion, we will suggest ways to improve the teaching of astronomy in Québec's elementary schools, hoping that they will be useful in other jurisdictions as well.

Although there has been earlier work that is now no longer timely, it is useful to know that two major surveys of science teaching by elementary teachers have been conducted in the past 15 years: Rowell \& Ebbers (2004), which surveyed science teachers in K-6 schools in Alberta, Canada, and the 2012 National Survey of Science and Mathematics Education (NSSME) (Banilower et al., 2013), this one conducted in the United States. A comprehensive bibliographical search revealed that no such studies have ever been conducted in Québec. Our search also turned up a few more studies specifically about astronomy teaching conducted in American high schools: Krumenaker (2008, 2009a, 2009b), Plummer \& Zahm (2010), Sadler (1992), and Slater, Slater, \& Olson (2009). In the following, we will describe findings by Rowell \& Ebbers (2004), the NSSME (Banilower et al., 2013), Slater, Slater, \& Olson (2009), and Plummer \& Zahm (2010), since we are mainly interested in the situation in elementary and middle schools, not high schools. Also, the reason we chose to explore Canadian and US studies exclusively is the great similarities between school systems from province to province and from state to state, making comparisons valid throughout. In each survey, we looked at the type of information collected and examined how they could be used to build our own questionnaire to answer our research questions. In the following, we briefly describe these studies and their major findings.

Rowell and Ebbers (2004) wanted to reveal the beliefs about, and perceptions of science teaching by elementary teachers in Alberta, Canada. Their survey focused on several components of science teaching at the elementary level: demographics, the teachers' goals in science teaching, their previous background and experience in S\&T, the resources and material they used (including classrooms and laboratories), their students' aptitudes and interests, and the type of community and professional support that was available to them. A comprehensive survey was mailed to about 3,000 elementary teachers in Alberta, 1,116 of which returned the questionnaire.

Rowell and Ebbers (2004) discovered that Alberta's elementary teachers are largely female, aged 35 years and older, and have on average more than 10 years of experience in teaching. The majority of teachers surveyed held a Bachelor's degree, did not study science beyond High school, and had no science-related employment experience before teaching. Alberta teachers reported that difficult institutional context (tight class schedule, for instance), insufficient physical facilities (inadequate classroom, for example), and the absence of adequate teaching equipment, were the most important obstacles they had to overcome to effectively teach science in their classrooms. Rowell and Ebbers' findings also show that elementary teachers predominantly teach science by using reading and writing material. In-service training is perceived as mostly ineffective or non-existent; when it is available, in-service training usually consists of informal conversations with colleagues.

The National Survey of Science and Mathematics Education (NSSME) conducted in 2012 in the United States (Banilower et al., 2013) studied many topics, like teachers' background and pre-service training, their beliefs about science teaching, their professional development, the way they make instructional decision, their teaching objectives, the resources they use, and other factors affecting instruction. In total, 7,752 teachers in elementary, middle, and high schools across the United States participated in this survey. The results suggest that elementary teachers' content preparation in science is rather weak, which explains why they don't feel well equipped to teach science in their classroom. Banilower (2013) and his colleagues link this situation to the fact that very few elementary teachers have had courses in science after high school. The researchers also report that, since elementary teachers typically teach several subjects other than science, and because teachers report that in-service professional development in science that is offered to them is rare and of average quality, staying informed and current about science development is particularly difficult for them.

In terms of time periods devoted to science teaching in elementary classroom, the NSSME found that elementary teachers teach science less frequently and for briefer periods of time than other subjects, like English and math. Science is taught most days every week in only one grades K-3 classroom out of five and in about a third of 
grades 4-6 classrooms, compared to almost $100 \%$ for math in K-6 classrooms. Science is taught on average about 20 minutes per day in grades K-3 and about 25 minutes per day in grades 4-6, compared to 86 minutes per day on average for English, and 56 minutes per day on average for math. The presence of specialist science teachers, either replacing or in addition to the regular elementary teacher, is unusual in most schools.

The NSSME also found that science textbooks, modules, or other science-related reading material is the major source of instruction in elementary science classes. Sixty-nine percent of elementary schools use science textbooks, and teachers recognize that they use them very frequently to organize their curriculum. We found comparable results in studies by Kesidou and Roseman (2002) and Hasni, Moreseli, Samson, and Owen (2009), illustrating the commonness of textbooks use in science teaching at the elementary level.

Finally, in terms of resources available in elementary schools to teach science, about $66 \%$ of teachers who completed the NSSME survey rated theirs as barely adequate or less. The survey also revealed the following problems: insufficient funds for buying equipment and supplies, the absence of science equipment in the school, not enough time to teach science in the class schedule, and not enough professional development opportunities for teachers.

In their survey, Slater, Slater, and Olson (2009) asked 799 K-12 teachers to describe if and how they were teaching astronomy, and to depict if and how they were using recent planetary science data in their classroom. Slater et al. found that the teachers they surveyed were highly engaged, innovative and motivated. Predictably for such highly dedicated teachers, the researchers found that they frequently consulted several web resources and other sources of data to stay up-to-date with astronomical research.

Finally, Plummer and Zahm (2010) questioned middle and high school science teachers using an online survey and conducted several interviews with curriculum directors. The researchers wanted to investigate how astronomical topics were covered in schools in the greater Philadelphia region of southeastern Pennsylvania. Plummer and Zahm (2010) wanted to know how astronomy is taught in these schools, and the characteristics of astronomy teachers in this region. Their study concentrated mainly on the coverage of state standards, the time spent on astronomy teaching in the classroom, the accessibility of resources, teacher efficacy, and teachers' educational views. Plummer and Zahm (2010) discovered that astronomy is taught only superficially in the schools they studied, and that many students go through their schooling in both middle and high school without learning any astronomy.

As we will see when we analyze our own data collected with our online survey, the situation described by Rowell and Ebbers (2004), Banilower and colleagues (2013) and the other studies presented in this section is very comparable to the one we found in Québec's elementary schools.

\section{METHOD}

\section{Instruments}

Our survey instrument was originally written in French (an English version of the questionnaire, translated by the author, can be found in the appendix) and consists of a 35-question form targeting the following topics, derived from our research questions and inspired by the surveys presented in the previous section:

- Questions 1 to 15 (all survey respondents): Demographics (age, gender); teaching experience; preservice education and training in science and technology; pre-teaching science and technology-related employment experience; astronomy and science teaching experience; number of hours per week of science teaching; demographics and socioeconomic information about the school, classroom, and students.

- Questions 16 to 25 (only survey respondents who teach astronomy): Integration of astronomy with other school topics (French, English, Math, etc.); astronomical topics taught; number of hours per year devoted to astronomy teaching; aims and goals of teaching astronomy; classroom arrangements, resources and equipment available; perceived obstacles to teaching astronomy. 
- Questions 26 to 35 (all survey respondents): Perceived efficiency of pre- and in-service training in astronomy, in science and technology, and in science teaching; perceived needs for in-service training in astronomy; self-interest in teaching astronomy; info about the survey.

A first version of the survey questionnaire was created in the Fall of 2013. Each survey question and multiple-choice answers were tested for readability with faculty colleagues and six volunteer $\mathrm{K}-6$ teachers. Once we reached a satisfactory version, the questions were transferred on an Pod $^{1}$ app designed by Logiciels Systamex. The final version of the iPod questionnaire contained 32 questions and multiple-choice answers and took approximately ten minutes to complete.

The online version of the survey was created in the Fall of 2014 by transferring the iPod version to LimeSurvey ${ }^{2}$, an Open Source web application that can be used to develop, publish and collect responses to surveys. Two questions of the original iPod questionnaire about respondent's previous studies in Physics and Chemistry were merged, since these two topics are mostly taught together in Québec's schools curriculum, and four questions were added to the online version: one concerning the presence in the respondent's school of a science specialist who's job is to teach science to all classes; one concerning the type of students in the classroom (regular, low income, disabled, etc.); one about the respondents practice of science leisure activities, which is a crude measure of one's scientific culture (Conseil des académies canadiennes [CAC], 2014; Godin \& Gingras, 2000); and one enquiring about how respondents came to know about the survey (email, Facebook page, School board memo, etc.). Thus, the 32question iPod survey, minus one, plus four, became a 35-question online survey. Like the iPod version, the online survey took about 10 minutes to complete.

\section{Participants}

Electronic messages inviting elementary school teachers all over the province to complete the survey online were sent in early January 2015 through various channels: Web sites, Facebook pages and monthly newsletters of Québec's two major professional teachers associations (not unions), AQEP and Association pour l'enseignement de la science et de la technologie au Québec, AESTQ; emails sent by these organizations directly to their members; emails sent by the AQEP congress organizers to past participants; emails redistributed by school boards, school directors and pedagogical councillors; and different message boards providing a link to the survey's welcome page. A paper published in January, 2015, in AQEP's professional magazine and presenting results of the 2013 iPod survey (Chastenay, 2015) also contained an invitation to complete the online survey.

From January to March, 2015, a total of 701 persons logged on the survey's welcome page and began answering questions, but only 500 completed the 35 questions. We compared all IP addresses collected by LimeSurvey and found no duplicates, proof that all respondents were unique visitors. It is interesting to note that the majority of those who did not complete the survey answered "No" to question 15 ("Did you teach any astronomy topic to your class during the last school year?"), and went no further. Although the invitation emails and the survey's welcome page insisted that even elementary teachers who do not teach astronomy were firmly invited to complete the survey nonetheless, it seems that a lot of respondents chose not to go beyond the admission that they did not teach astronomy to their class. This anecdotal information leads us to believe that the fraction of elementary teachers in our survey who do not teach astronomy is probably underestimated (or, to say it differently, "Astronomy teachers" are probably over represented in our sample). Of course, since ours is a convenience sample, we cannot pretend that our results are a statistically perfect illustration of the situation of astronomy teaching in Québec's schools. Nonetheless, with 500 respondents, we can clearly see patterns and trends emerging from our results; we will describe and analyze them in the following section.

\section{RESULTS}

In this section, we will present the results obtained by analyzing survey responses from the 500 online respondents. We will first describe the demographics of our sample and the characteristics of the schools where they teach (Part 1 , below), then analyse the questions that were answered only by those elementary teachers that teach astronomy to

$1 \mathrm{iPod} \odot$ is a trademark of Apple Computer Corp.

${ }^{2} \mathrm{https}: / /$ www.limesurvey.org

Copyright by author(s); $\underline{\text { CC-BY }}$ 
their class ("Astronomy teachers", Part 2). Finally, we will complete the presentation of results with answers from all respondents to the last questions of the survey about pre-service and in-service training (Part 3).

To calculate the uncertainty range of our data at the $95 \%$ confidence interval, we used the approximate formula $\frac{0,98}{\sqrt{N}}$ (Howell, 1998). For questions 1-15 (Part 1) and questions 26-35 (Part 3), that were answered by all respondents, $\mathrm{N}=$ 500 and the uncertainty range is $\pm 4 \%$. For questions $16-25$, that were answered only by astronomy teachers (Part 2 ), $\mathrm{N}=244$ and the uncertainty range becomes $\pm 6 \%$. Error bars representing these uncertainty ranges will be added to figures throughout.

\section{Part 1: Elementary Teachers' Demographics and Schools Characteristics}

We were not surprised to find out that our sample of elementary teachers is very predominantly composed of women (91\%), $42 \%$ of them aged between 35 and 44 years old (25\% are aged between 25 and 34 years old, and $24 \%$ between 45 and 54). Accordingly, 49\% have between 11 and 20 years of experience teaching at the elementary level. All have completed a Bachelor's degree in Education (four years), but only 17\% achieved a Master's degree and $1 \%$ hold a Ph.D. These demographics are essentially similar to elementary teachers demographics available from MÉLS (2013).

Only $8 \%$ of respondents have had pre-teaching employment experience in a scientific environment, and for most of them, it was working in a science museum. Also, the most popular practice of scientific culture among respondents is listening to TV and radio shows about science, and reading scientific web sites. The practice of a scientific leisure activity, like amateur astronomy, bird watching, or insect collecting, seems rather uncommon among elementary teachers (only $6 \%$ of respondents). Overall, these results are very similar to what Rowell and Ebbers (2004) and Banilower et al. (2013) have found with their own surveys of Albertan and American elementary teachers.

One important result of our survey concerns the grade level at which respondents took their last courses in Physics and Chemistry, Biology, Geography and History, and Mathematics, respectively (see figure 1): $74 \%$ did not study physics nor chemistry after high school, and $58 \%$ did not study biology beyond that point neither. Note that in figure 1, Cegep stands for Collège d'enseignement général et professionnel: it represents the first stage of higher education in Québec, in which students enter after completing high school (Grade 12), and before entering university. Our results show that the sample of elementary teachers who answered our survey typically studied the Humanities (including History and Geography) in a two-year pre-university program in Cegep before entering university.

Figure 1. Elementary teachers' highest level of education with courses completed in Physics and Chemistry, Biology, History and Geography, and Math ( $\mathrm{N}=500$, uncertainty range $\pm 4 \%)$

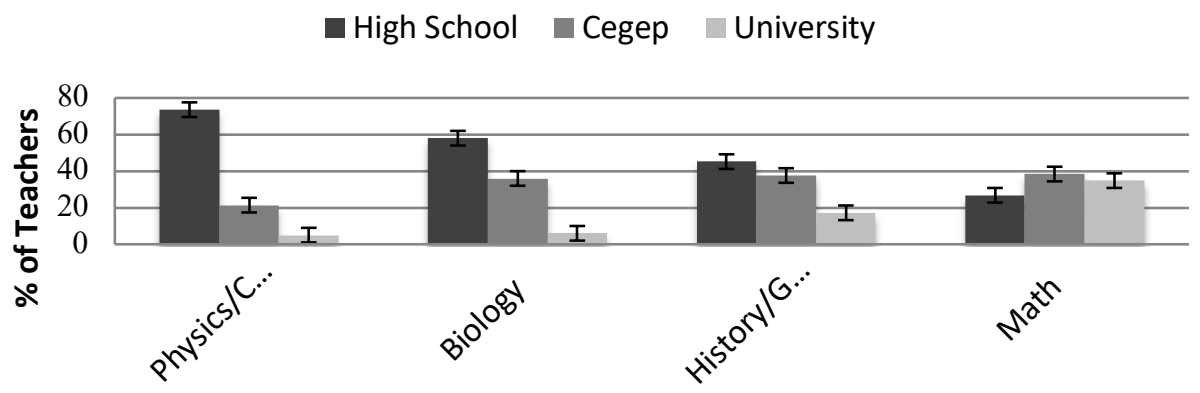

Highest level of education with courses completed

Our results also show that $87 \%$ of respondents teach full time and that $71 \%$ teach to a class of 16 to 25 students, which is typical of a regular elementary class in Québec (MÉLS, 2013). Respondents are also evenly distributed between grades 1 to 6 (about 23\% each, including multiple level teaching), except for Kindergarten teachers (16\%), who are less numerous among those who took the survey. Also, it appears from our data that a specialized teacher devoted to teaching science to all classes in one school is the exception rather than the norm (only $4 \%$ of respondents have one at their school). 
The school where respondents work are predominantly urban (33\%) and suburban (44\%), which reflects the makeup of the general population in the province of Québec, according to the most recent census data available (Statistiques Canada, 2011). The majority of teachers surveyed teach to a regular class (78\%), although $37 \%$ rate theirs as underprivileged, and $19 \%$ are teaching to students with behaviour problems. To measure the socioeconomic status of the students in a school, Québec's Ministry of Education uses the Index of Socio-Economic Background (ISEB). The ISEB contains two variables: the level of education of the mother, and the employment status of the parents. According to MÉLS (2014), these two variables are the strongest predictors of a children's achievements in school. This index uses a scale of 1 to 10, 1 being the most privileged and 10 the most underprivileged. In 2014, the median ISEB for the 1,636 elementary schools in Québec was 6 (data from MÉLS, 2014, compiled by the author), whereas the median for our sample is slightly less privileged at 7. It is worth noting, though, that a third of the respondents to our survey didn't know the ISEB of their school.

Figure 2 shows the number of hours per week that respondents declare teaching science in their class. Seven percent admit not to teach science at all in their classroom, whereas the majority $(68 \%)$ teach science less than 1 hour per week. In fact, $94 \%$ of the teachers sampled in our survey say they teach science less than two hours per week.

Figure 2. Number of hours of science teaching per week $(\mathrm{N}=500$, uncertainty range $\pm 4 \%)$

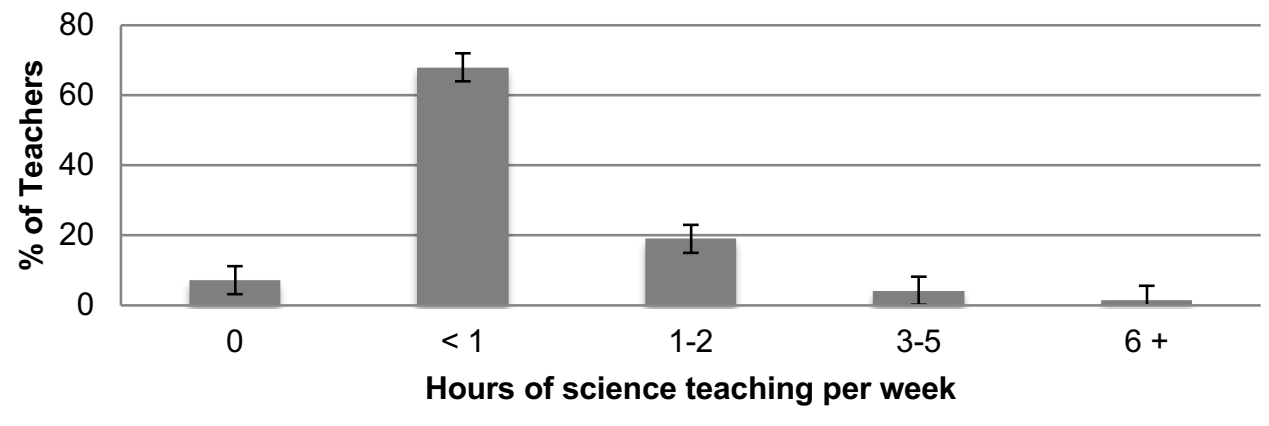

Finally, when asked if they have taught astronomy to their class during the last school year, 49\% answered yes, a result that may be artificially high compared to the general population of elementary teachers, due to the conditions in which the online survey was conducted and the apparent withdrawal of Non-astronomy teachers after answering No to question 15. In the next section, we will examine the answers given to questions 16 to 25 by these "Astronomy teachers".

\section{Part 2: The Case of Astronomy Teachers}

We first asked Astronomy teachers if they combined their teaching of astronomy with another subject, like French, math, arts, etc., or as a separate topic. Thirty-four percent said they teach astronomy with another topics, most predominantly French (87\%). Math (39\%) and Arts (38\%) are far second in terms of integration with astronomy, followed by Information Technology and Telecommunications (27\%), and History and Geography $(22 \%)$.

As for the astronomy topics covered in the classroom, we find the usual suspects (see figure 3; note that more than one answer was allowed, so the total is superior to 100\%). These topics reflect the content of Québec's curriculum for elementary schools, which teachers seem to follow well. 
Figure 3. Astronomical topics taught in the elementary classroom $(\mathrm{N}=244$, uncertainty range $\pm 6 \%)$

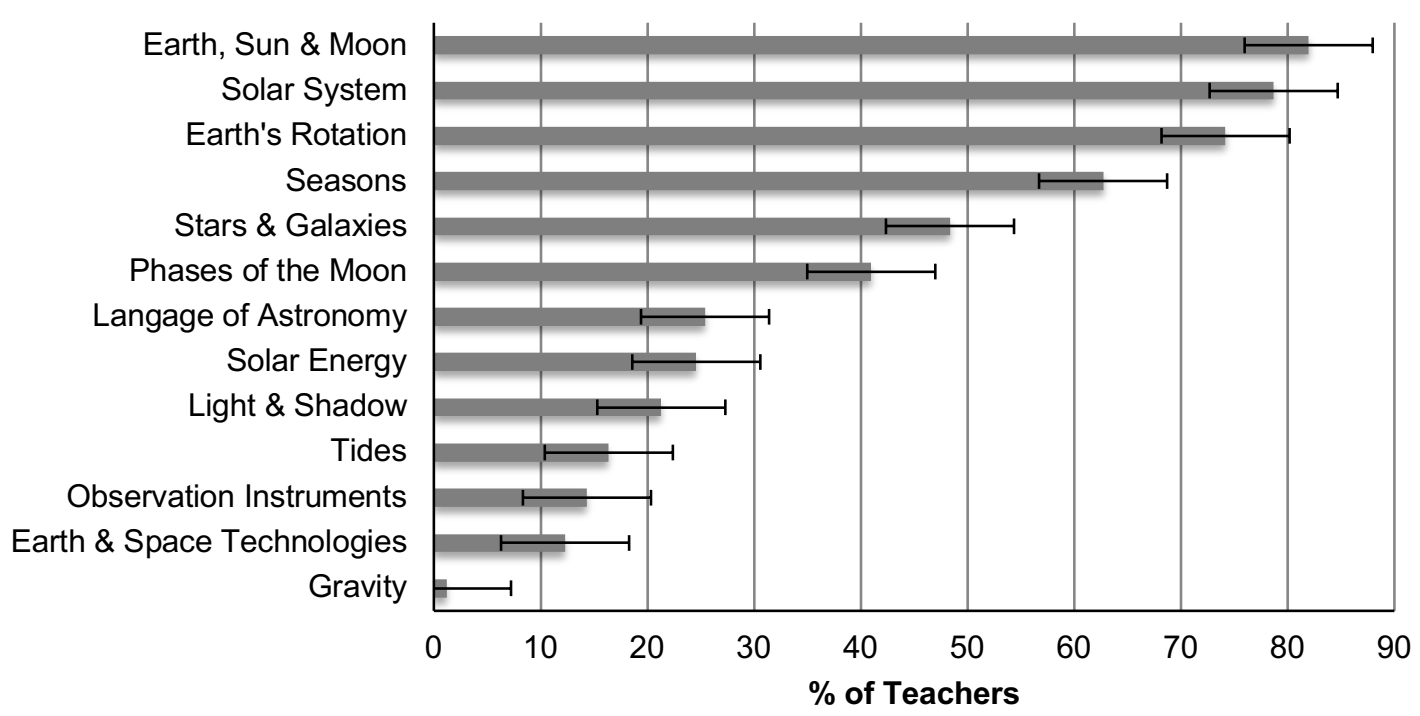

According to our survey, the majority of astronomy teachers in our sample teach astronomy less than 10 hours per year (67\%, see figure 4), although about one in five teach between 11 and 20 hours of astronomy per year.

Figure 4. Number of hours of astronomy teaching per year $(\mathrm{N}=244$, uncertainty range $\pm 6 \%)$

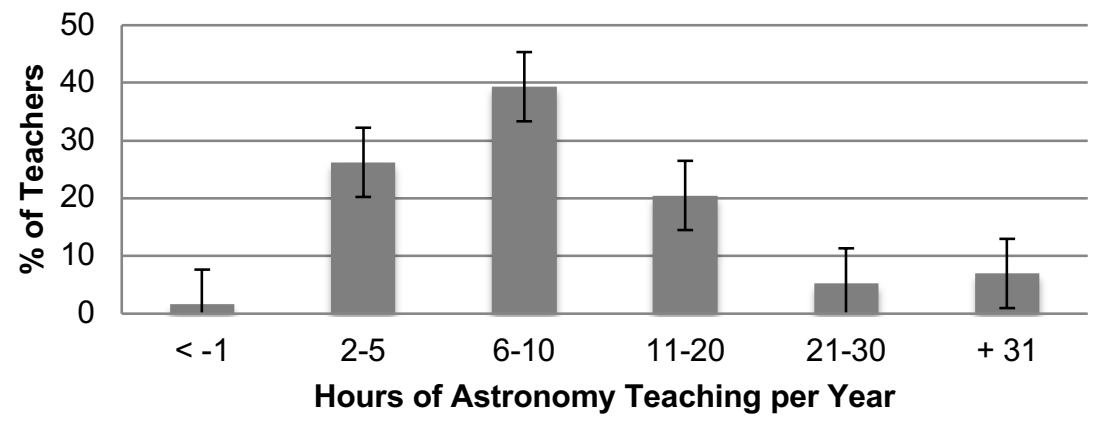

We then probed astronomy teachers about their aims and goals when teaching astronomy, by asking them to rate twelve statements in terms of the importance they give to each (see figure 5). These statements were composed to reflect teaching goals contained in Québec's curriculum for elementary schools. Among the statements rated highest in terms of importance, we find "I teach astronomy to my students to cover the curriculum", "To help them learn astronomy concepts", "To develop their scientific attitude", and "To develop my students' know-how in science". Other statements that were rated a little less important are "I teach astronomy to my students to help them discover the importance of astronomy in their lives", "To develop my students" competencies", and "To develop their reading and writing skills". The statements "I teach astronomy to my students to help them discover the tools of astronomy" and "To develop my students' social skills" were considered important by about half of respondents. 
Figure 5. Aims and goals of astronomy teaching $(N=244$, uncertainty range $\pm 6 \%)$

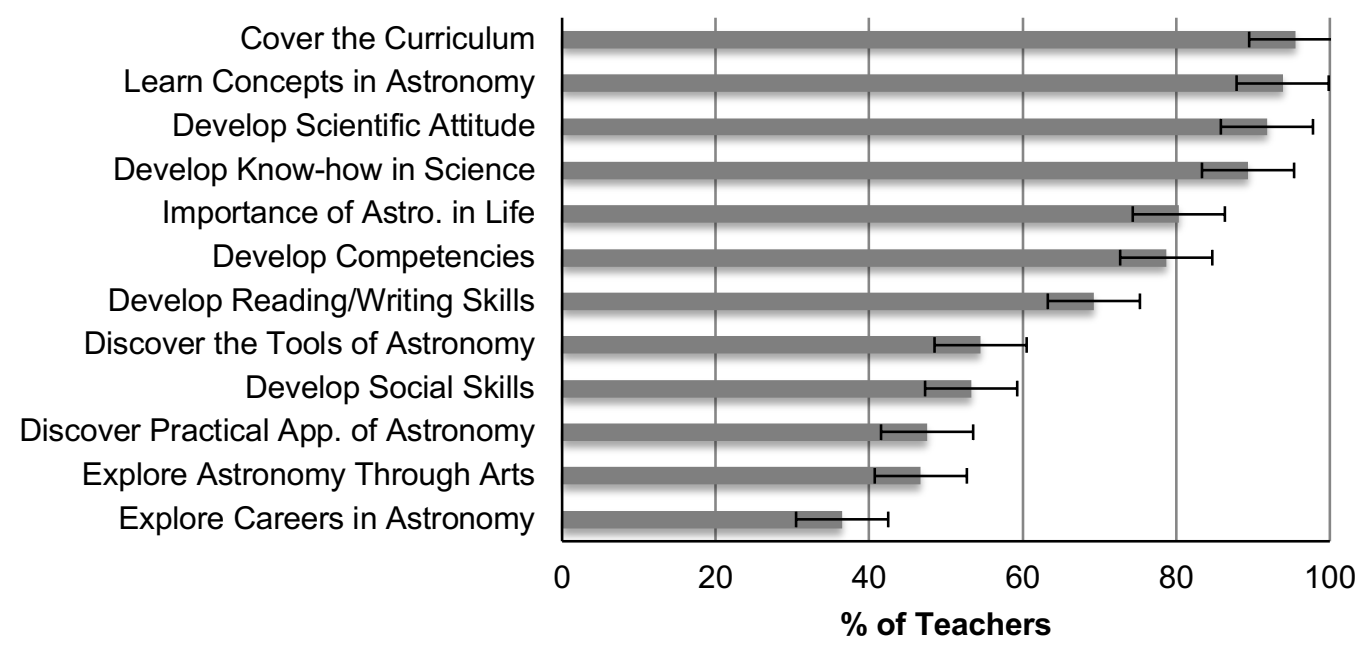

We asked Astronomy teachers if they had ever experienced any difficulties teaching astronomy to their class (see figure 6); $30 \%$ said they had not. Others pointed to the lack of resources and materials, their self-perceived lack of training and experience in astronomy teaching, the lack of time in the class schedule (remember that astronomy is not a mandatory subject in Québec's elementary schools curriculum), and inadequate classroom arrangement as sources of difficulties. It is worth noting that $23 \%$ of Astronomy teachers said they felt incompetent teaching astronomy to their class. Students not interested, lack of support from school, and students with difficulties were not considered as sources of difficulty in teaching astronomy.

Figure 6. Sources of difficulty in teaching astronomy to the class $(\mathrm{N}=244$, uncertainty range $\pm 6 \%)$

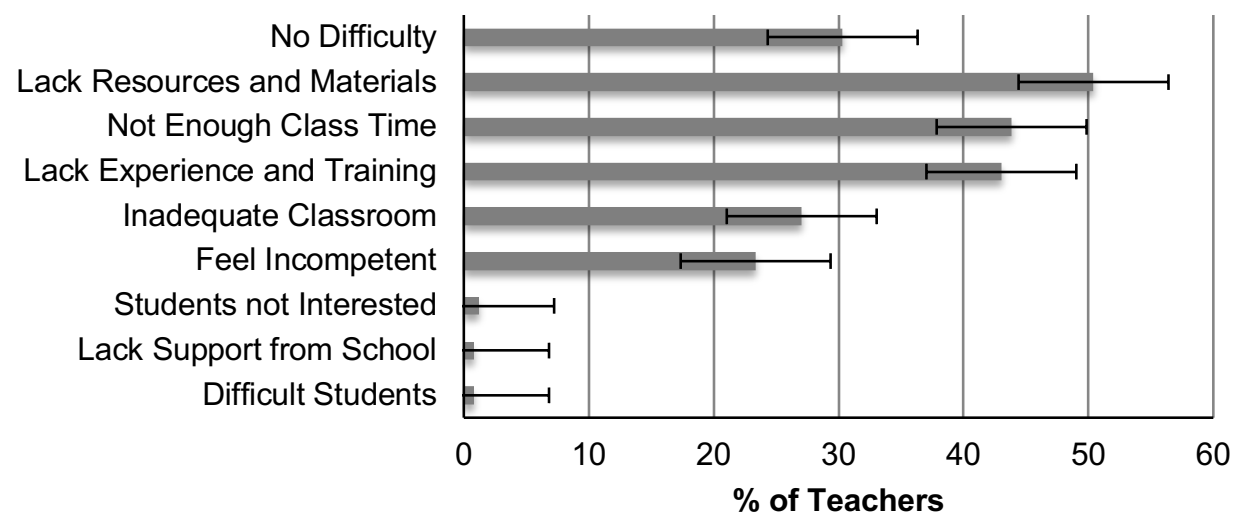

What kind of materials do Astronomy teachers use in their classroom? A look at figure 7 shows that the most popular items are the Internet, trade books, textbooks, and scale models, like an Earth globe or an orrery. The places where astronomy is done and the tools of the astronomer, i.e. visit to observatory and planetarium, binoculars, telescopes, and astronomy software, are among the less popular, which might reflect budget and resource limitations on the part of the school, but also teachers' lack of knowledge and experience about how to use them to teach astronomy. The importance of Internet, trade books and textbooks might also be an indication that the teaching of astronomy in Québec's elementary schools is mostly a read-and-write activity, with students and teachers relying heavily on textbooks and activity sheets to cover the topics included in the curriculum (Hasni et al., 2009). This trend is reinforced by the fact that the topic with which astronomy teaching is most often integrated is French (see above). 
Figure 7. Materials used to teach astronomy $(\mathrm{N}=244$, uncertainty range $\pm 6 \%)$

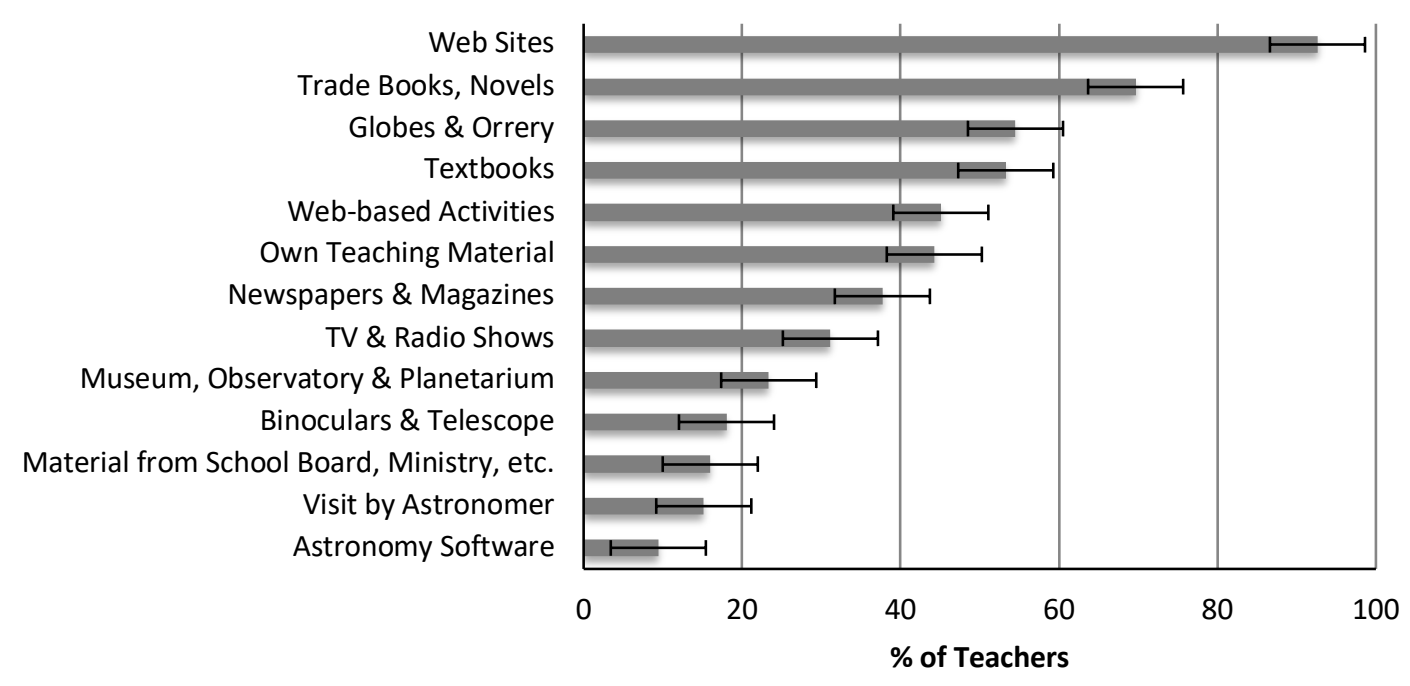

Where do Astronomy teachers perform their duties? Mostly in a regular classroom equipped with A/V equipment (76\%). Access to a special classroom for experiments and demonstrations (for instance, a dark room), or a laboratory classroom, seems to be the exception. In terms of resources and equipment used to teach astronomy, results show that the situation is rather inadequate, with $58 \%$ of respondents complaining the lack thereof, and only $2 \%$ expressing their satisfaction with what they have. A/V equipment and computer rooms are available to about half respondents, and about a fifth complain that they only have access to cheap, old and poor quality equipment. Astronomy software (7\%), demonstration and observation equipment (2\%) seem to be mostly absent from elementary astronomy classrooms.

Finally, we asked Astronomy teachers to rate the overall quality of the equipment and the resources at their disposal to teach astronomy. Figure 8 shows that the result is rather poor: only $21 \%$ rate it either excellent or good, while $71 \%$ say it's poor or mediocre; $7 \%$ complain they don't have access to such material in the first place.

Figure 8. Perceived quality of the equipment and the resources used to teach astronomy $(\mathrm{N}=244$, uncertainty range $\pm 6 \%)$

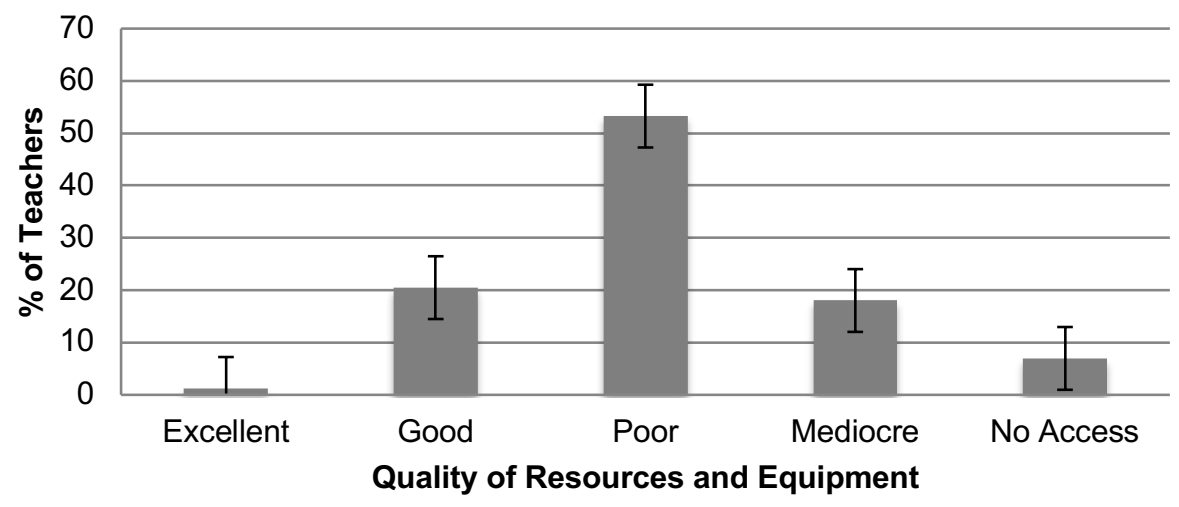




\section{Part 3: Pre-service and In-service Training}

We asked all respondents (Astronomy and Non-astronomy teachers) to answer a series of questions about their level of satisfaction toward pre-service (university) training in astronomy, in science and in science teaching (see figure 9). It turns out that most elementary teachers did not receive any training in astronomy at all while they were university undergraduates, and that in terms of pre-service science and science teaching training, the level of satisfaction is quite low: $59 \%$ and $55 \%$ of respondents are either unsatisfied or very unsatisfied with the training they received at university level in science and in science teaching, respectively.

Figure 9. Level of satisfaction toward pre-service (university) training in astronomy, in science and in science teaching ( $\mathrm{N}=500$, uncertainty range $\pm 4 \%$ )

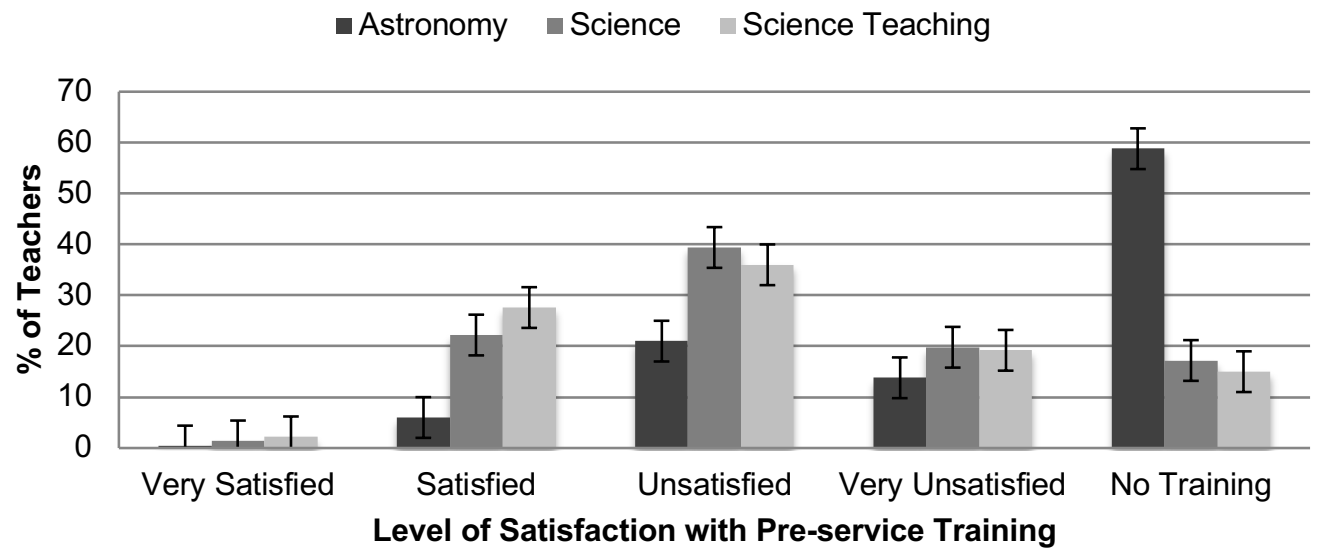

What about in-service training? We asked respondents to describe the type of in-service training in astronomy that is available to them on a regular basis. Fifty-nine percent said that there is none (see figure 10). Others mentioned informal discussion with colleagues (21\%), training offered either by the school, school board or Ministry of Education (15\%), or meeting (10\%) and training $(9 \%)$ with amateur and/or professional astronomers. University courses, either in science teaching or in astronomy, and meeting and training with science teaching specialists, don't seem to be an option available to most elementary teachers. And figure 11 shows that, for the few who had access to in-service training in astronomy, the training seems to be mostly ineffective or very ineffective.

Figure 10. Type of in-service training in astronomy available to elementary teachers $(\mathrm{N}=500$, uncertainty range $\pm 4 \%)$

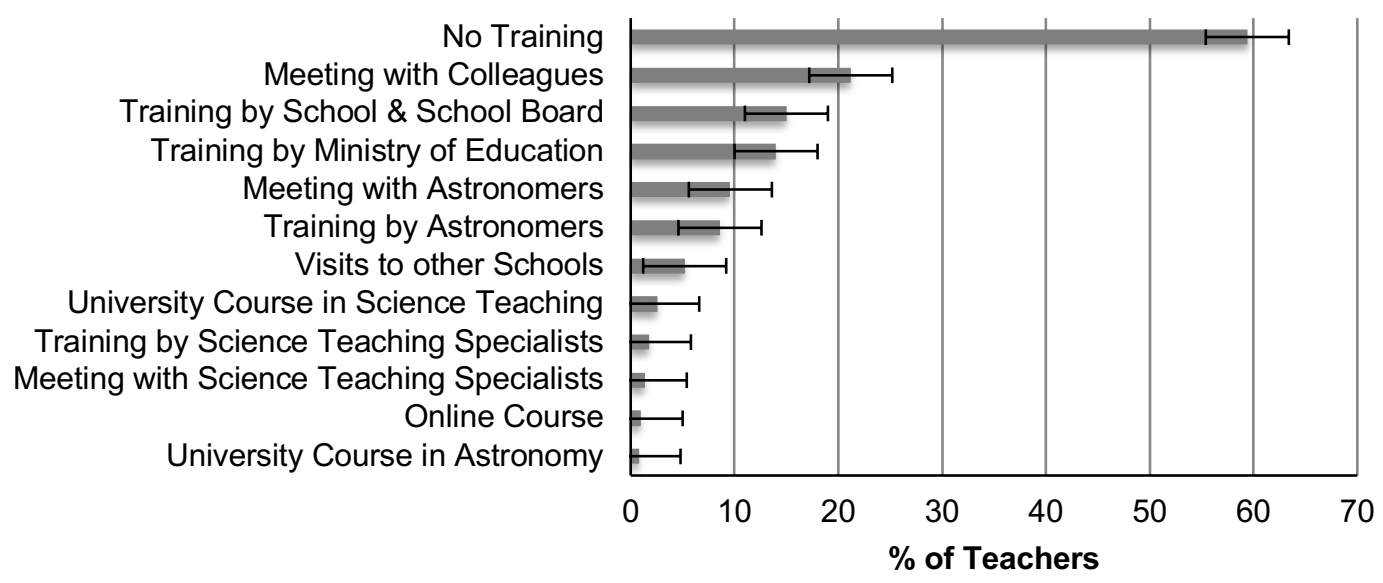

Copyright by author(s); $\underline{\text { CC-BY }}$ 
Figure 11. Perceived effectiveness of in-service training in astronomy $(\mathrm{N}=500$, uncertainty range $\pm 4 \%)$

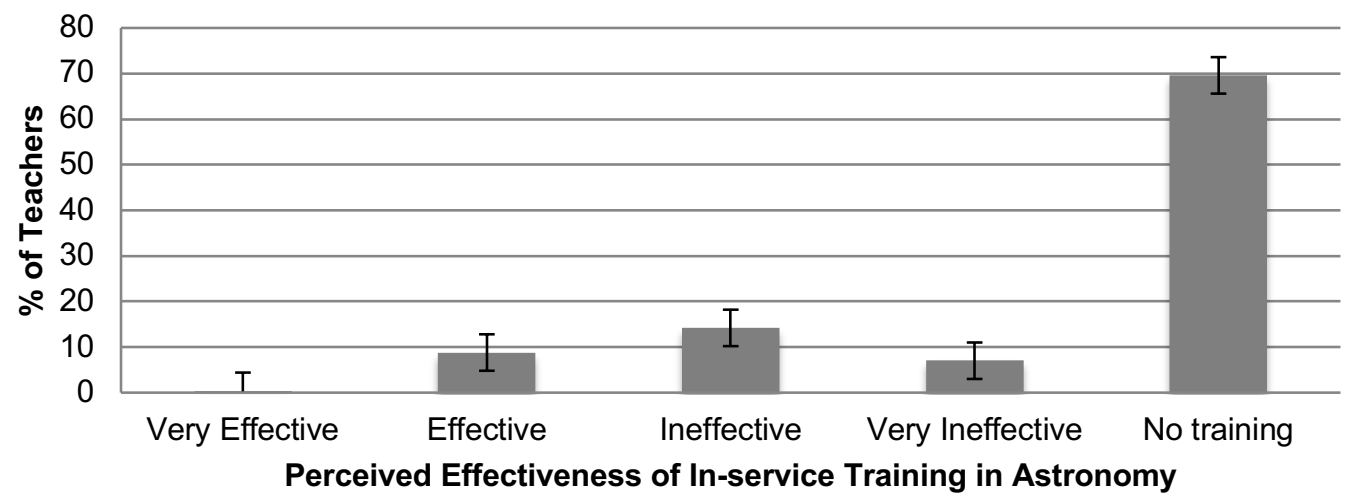

When would be the best time to offer in-service training to elementary teachers? According to figure 12, it is definitely during normal school hours (with a teacher replacement) or during professional development (PD) days. After school hours, Spring break and Summer vacations are not very popular among respondents to our survey.

Figure 12. Best time to offer in-service training to elementary teachers $(\mathrm{N}=500$, uncertainty range $\pm 4 \%)$

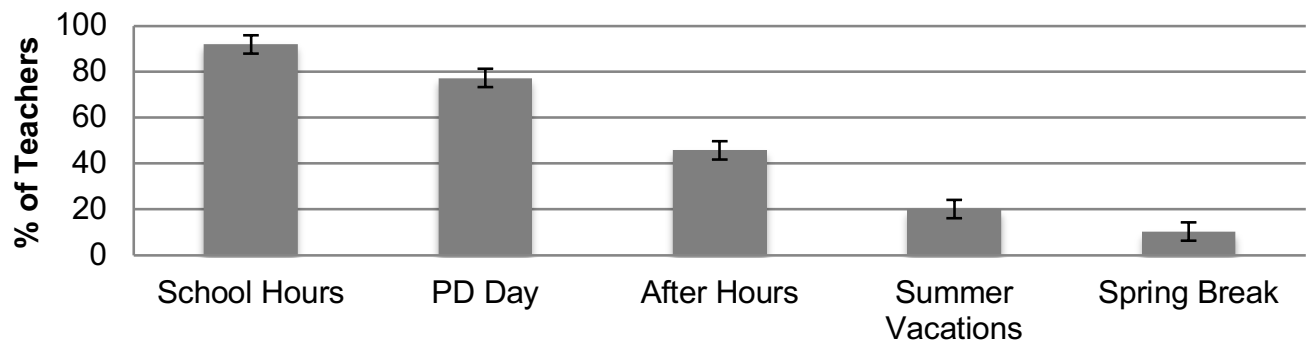

Best Time for In-Service Training

When asked how much training in astronomy elementary teachers feel they need, the majority would rather receive a one-day session $(59 \%)$ or a weeklong course $(35 \%)$. Very few, of course, feel that they don't need in-service training in astronomy.

Finally, we asked all survey respondents if they would prefer not to teach astronomy in their classroom, if they had the choice; only $17 \%$ said yes. We further asked these 86 elementary teachers why would they choose not to teach astronomy. Figure 13 shows that the main reasons are deficient pre-service training, lack of resources to teach astronomy and lack of in-service training. Other reasons include not feeling competent enough to teach astronomy, and the extra time needed to help underachieving students, or to teach more of the core subjects, like French and Math. Also, tight class schedule and the perceived difficulty of doing "hands-on experiments" in astronomy seems to be factors that lead to a neglect of astronomy teaching. Fortunately, a lack of interest toward astronomy on the part of elementary teachers, or fears that students will know more than they do, don't seem to play a role in that decision. 
Figure 13. Reasons not to teach astronomy $(\mathrm{N}=86$, uncertainty range $\pm 11 \%)$

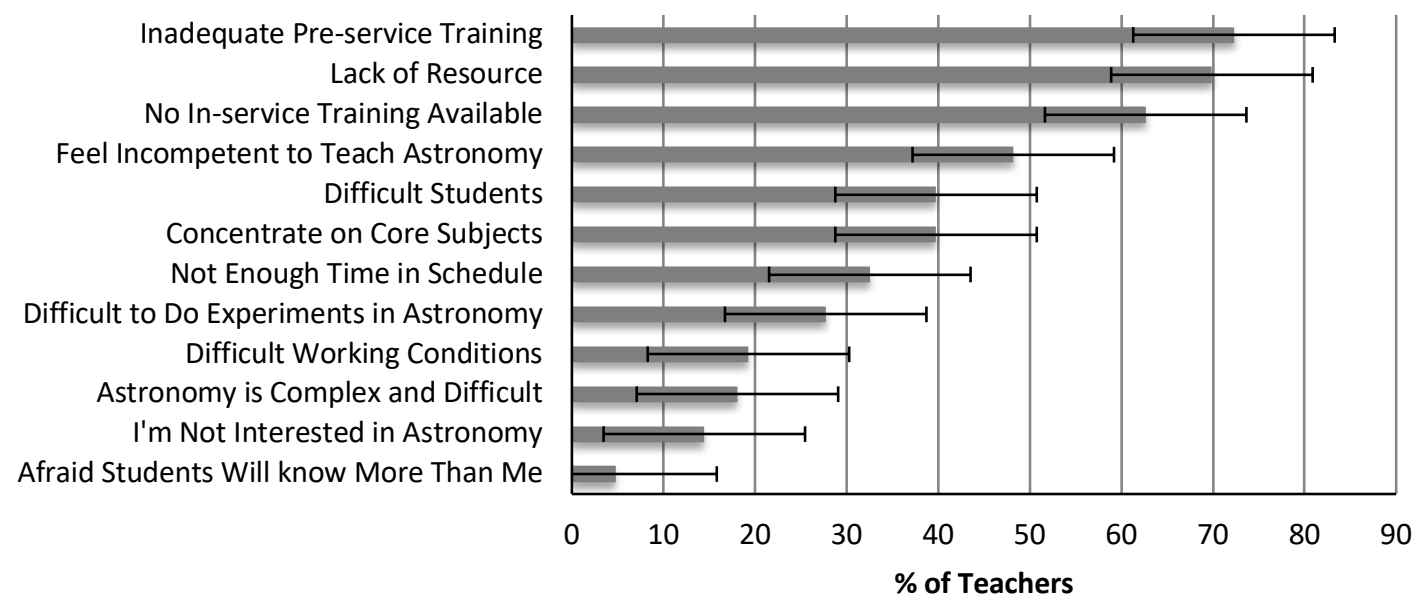

DISCUSSION AND CONCLUSION

Using an anonymous, online survey instrument, we questioned 500 in-service elementary teachers about the way they teach astronomy, the topics they cover, the materials they use, their pre-service as well as in-service training in astronomy and in science, and the problems they encounter while teaching astronomy, all in an effort to determine the reasons some elementary teachers prefer not to teach astronomy in their classroom, and try to find ways to help teachers feel more confident teaching this topic.

By comparing with data from MÉLS (2013), we find that the demographics of our sample is very similar to the general population of elementary school teachers in Québec: respondents are mostly female, aged between 35 and 44 years old, and with 11 to 20 years of teaching experience. Most respondents hold a bachelor's degree in Education. The school where they teach, its socioeconomic and geographical location, the type of classroom, and their students' makeup, all are representative of Québec's typical elementary school.

Very few respondents have had a pre-teaching job experience in a science-related environment or participate in a science-related leisure activity. Preferred science culture activities are watching and listening to science TV and radio shows and visiting scientific web sites. For most of our survey's respondents, the study of science, like physics, chemistry or biology, didn't go beyond high school. The vast majority teach science less than 2 hours per week, and 51\% admit they don't teach astronomy at all in their classroom, although this figure is probably underestimated, since a large number of people who logged on the survey's web page and admitted not teaching this subject have simply not completed the questionnaire.

Teachers who do teach astronomy to their class seem to cover the topics contained in Québec's elementary schools curriculum well, even though the majority of Astronomy teachers devote less than 10 hours per year to these subjects. Their aims and goals in astronomy teaching are also well aligned with Québec's school program objectives, which are to help students develop their competencies and learn core knowledge. But astronomy teachers meet with a lot of difficulties: lack of resources and materials, old equipment of poor quality, lack of training, inadequate classroom arrangement, not enough time in the class schedule, as well as their own feeling of being incompetent to teach the subject adequately.

A telling result is the choice of Internet, trade books, textbooks, and other reading material as the tools used by the majority of Astronomy teachers to teach astronomy. This tends to show that astronomy teaching in Québec's elementary schools is mostly done through reading and writing activities, and not through observing the sky, looking for patterns, making notes, gathering data and modelling, as is proposed by many astronomy education specialists (viz., Agan \& Sneider, 2007; Chastenay, 2017; Kallery, 2011; Kavanagh, Agan \& Sneider, 2005; National Research Council, 1996; Sneider, Bar \& Kavanagh, 2011). 
Our results show that pre-service training in astronomy was unavailable for the majority of respondents to this survey; since astronomy was introduced only recently in Québec's elementary school curriculum, this should not come as a surprise. What is more worrying is the very low level of satisfaction expressed by teachers toward preservice training in science and in science teaching. Also troubling is the fact that in-service training in astronomy is mostly absent or, when available, seems to be mostly ineffective, even though the majority of respondents think they only need a few hours or days of training to feel competent enough to teach the topic in class.

These last results might help explain why $17 \%$ of teachers surveyed admit they would prefer not teach astronomy to their class. The reasons they give are all congruent with what we wrote previously about the difficulties of teaching astronomy in elementary school, like the absence or the poor quality of pre-service and in-service training. A lot of teachers prefer to devote more class time to core subjects, like French and Math, which are incidentally the subject of province-wide Ministry of Education tests in Grade 4. Remember that in Québec, astronomy is not mandatory at the elementary level.

Based on these results, it seems that the absence of pre-service training in astronomy, the lack or the poor quality of in-service training in astronomy, the lack of resources and equipment, and the feeling of not being competent enough to teach astronomy in the classroom are the main factors that hinder astronomy teaching in Québec's K-6 classrooms. To counter that situation, we propose a series of measures that could help ensure that more elementary teachers do teach astronomy to their class:

- Offer high-quality pre-service training in astronomy to future elementary teachers;

- Offer high-quality in-service training in astronomy to actual elementary teachers, at a time convenient for them (class time, PD days) and with an appropriate duration (one day to one week);

- Offer high quality resources and materials to elementary teachers interested in teaching astronomy in their classroom.

We believe that promoting such measures will give elementary teachers the training and tools they need to feel competent enough to efficiently teach astronomy to their students, and that this will ultimately lead to better astronomy teaching in elementary classrooms across Québec. We also believe that the same measures could be promoted in other jurisdiction (provinces or states) in which astronomy teaching at elementary level is lacking.

If such measures are indeed implemented, it could be useful to repeat the survey in 5 to 10 years to measure their impact. Also, since the introduction of astronomy in Québec's school curriculum in 2006-2007, pre-service training programs offered by several Faculties of Education across the province have been modified to include astronomy; a repeat of the survey in about 10 years will allow us to measure the effectiveness of these new pre-service programs on the population of Québec's elementary teachers.

\section{ACKNOWLEDGMENTS}

The author wishes to thank AQEP and AESTQ for facilitating access to elementary teachers invited to participate in the survey. Thanks also go to François Thibault, Alexandra Bolduc and Hugo G. Lapierre for their help analyzing the data. This research was authorized by a Certificate of ethics nr S-703492 and was supported by a UQAMPAFARC grant.

\section{AUTHOR BIOGRAPHY}

Pierre Chastenay holds a M.Sc. in astrophysics from Université Laval and a Ph.D. in science education from Université de Montréal. After 25 years as Director of Education at the Planétarium de Montréal, he is now a professor of science education at Université du Québec à Montréal, where his main research interests are science and astronomy education, and primary teacher training. 


\section{REFERENCES}

Agan, L., \& Sneider, C. (2004). Learning about the earth's shape and gravity: A guide for teachers and curriculum developers. Astronomy Education Review, 2(2), 90-117.

Banilower, E. R., Smith, P. S., Weiss, I. R., Malzahn, K. A., Campbell, K. M., \& Weis, A. M. (2013). Report of the 2012 National Survey of Science and Mathematics Education. Chapel Hill: Horizon Research, Inc.

Chastenay, P. (2014). The state of astronomy teaching in Québec's primary and elementary schools: A survey of teachers. Journal and Review of Astronomy Education and Outreach, 1(2), A3-A40.

Chastenay, P. (2015). L'enseignement de l'astronomie au Québec : résultats d'un sondage mené auprès d'enseignants du primaire. Vivre Le Primaire, 28(1), 50-52.

Chastenay, P. (2017). La didactique de l'astronomie. In S. El Euch, A. Groleau \& G. Samson (Eds.), Didactiques: bilan et perspectives. Québec: PUQ.

Conseil des académies canadiennes. (2014). Culture scientifique: qu'en est-il au Canada ? Ottawa: Le comité d'experts sur l'état de la culture scientifique au Canada, Conseil des académies canadiennes.

Godin, B., \& Gingras, Y. (2000). What is scientific and technological culture and how is it measured? A multidimensional model. Public Understanding of Science, 9(1), 303. http://doi.org/10.1088/0963-6625/9/1/303

Hasni, A., Moreseli, C., Samson, G., \& Owen, M.-E. (2009). Points de vue d'enseignants de sciences au premier cycle du secondaire sur les manuels scolaires dans le contexte de l'implantation des nouveaux programmes au Québec. Revue des sciences de l'éducation, 35(2), 83-105.

Howell, D. C. (1998). Méthodes statistiques en sciences humaines. Bruxelles: De Boeck Université.

Kallery, M. (2011). Astronomical concepts and events awareness for young children. International Journal of Science Education, 33, 341-369. http://doi.org/10.1080/09500690903469082

Kavanagh, C., Agan, L., \& Sneider, C. (2005). Learning about phases of the Moon and eclipses: A guide for teachers and curriculum developers. Astronomy Education Review, 4(1). http://doi.org/10.3847/AER2005002.

Kesidou, S., \& Roseman, J. E. (2002). How well do middle school science programs measure up? Findings from Project 2061's curriculum review. Journal of Research in Science Teaching, 39(6), 522-549. http://doi.org/10.1002/tea.10035

Krumenaker, L. (2008). High school planetariums - Results of a survey. Planetarian, 37(4), 17.

Krumenaker, L. (2009a). The modern U.S. high school astronomy course, its status and makeup, and the effects of No Child Left Behind. Astronomy Education Review, 8. http://doi.org/10.3847/AER2009042

Krumenaker, L. (2009b). The modern U.S. high school astronomy course, its status and makeup II: Additional results. Astronomy Education Review, 8. http://doi.org/10.3847/AER2009052

Ministère de l'Éducation, du Loisir et du Sport [MÉLS] (2007). Programme de formation de l'école québécoise, enseignement secondaire, deuxième cycle. Québec: Gouvernement du Québec.

Ministère de l'Éducation, du Loisir et du Sport (2013). Rapport annuel de gestion 2012-2013. Québec: Gouvernement du Québec.

Ministère de l'Éducation, du Loisir et du Sport (2014). Indice de milieu socio-économique (IMSE). Retrieved from http://www.mels.gouv.qc.ca/enseignants/integration/milieu-defavorise/agir-autrement/indice-de-milieu-socioeconomique-imse/

Ministère de l'Éducation du Québec [MÉQ] (2006a). Le programme de formation de l'école québécoise, éducation préscolaire, enseignement primaire. Québec: Gouvernement du Québec.

Ministère de l'Education du Québec (2006b). Programme de formation de l'école québécoise, enseignement secondaire, premier cycle. Québec: Gouvernement du Québec.

National Research Council (1996). National science education standards. Washington, DC: National Academics Press.

Plummer, J. D., \& Zahm, V. M. (2010). Covering the standards: Astronomy teachers' preparation and beliefs. Astronomy Education Review, 9(1). http://doi.org/10.3847/AER2009077

Rowell, P. M., \& Ebbers, M. (2004). Elementary science education in Alberta schools. Edmonton: Center for Mathematics, Science and Technology Education, University of Alberta.

Sadler, P. M. (1992). High school astronomy: Characteristics and student learning. In C. Pennypacker (Ed.), Workshop on handson astronomy for education. Tucson: World Scientific.

Slater, S. J., Slater, T. F., \& Olson, J. K. (2009). Survey of K-12 science teachers' educational product needs from planetary scientists. Astronomy Education Review, 8.

Sneider, C., Bar, V., \& Kavanagh, C. (2011). Learning about seasons: A guide for teachers and curriculum developers. Astronomy Education Review, 10(1). http://doi.org/10.3847/AER2010035

Statistiques Canada (2011). Population urbaine et rurale, par province et territoire (Québec). Retrieved from http://www.statcan.gc.ca/tables-tableaux/sum-som/102/cst01/demo62f-fra.html

Thouin, M. (2015). L'astronomie dans le Programme de formation de l'école québécoise et dans la classe. Vivre Le Primaire, 28(1), 47-49. 


\section{APPENDIX}

\section{List of questions used in the survey}

Note: This survey was translated from the French version by the author.

1. Do you agree to take this survey? Check one.
a. Yes (Go to Question 2)
b. No (You're done! Thank you for your cooperation.)

2. You are... Check one.
a. A woman
b. A man

3. In what age group are you? Check one.
a. 18-24 years old
b. 25-34 years old
c. $35-44$ years old
d. $45-54$ years old
e. 55-64 years old
f. 65 years old and over

4. How many years of experience do you have teaching elementary school, including the present school year, either part-time or full-time? Check one.
a. Less than a year
b. 2-5 years
c. 5-10 years
d. 11-20 years
e. 21-30 years
f. More than 30 years

5. What is the highest level of education that you have completed? Check one.
a. Undergraduate Certificate (30 credits)
b. Undergraduate Short Program (15 credits)
c. Graduate Short Program (15 credits)
d. B.Ed. (Elementary school)
e. B.Ed. (High school)
f. B.Ed. (school adaptation)
g. $\mathrm{DESS}^{3}$
h. M.Ed.
i. Ph.D.

6. Indicate the highest grade in which you have taken courses in the following disciplines:

\begin{tabular}{|ll|l|l|l|}
\hline a. & Mathematics & High school & Cegep $^{4}$ & University \\
\hline b. Physics \& Chemistry & High school & Cegep & University \\
\hline c. Biology & High school & Cegep & University \\
\hline d. History & High school & Cegep & University \\
\hline e. & Geography & High school & Cegep & University \\
\hline
\end{tabular}

${ }^{3}$ DESS (Diplôme d'études supérieures spécialisées) is a post-Bachelor degree, equivalent to a M.Ed., but without a Memoir. ${ }^{4}$ Cegep (Collège d'enseignement général et professionnel) is a two-year preparatory school before entering university. 
7. What grade do you teach during the current school year? Mark as many as necessary.
a. Kindergarten
b. Grade 1
c. Grade 2
d. Grade 3
e. Grade 4
f. Grade 5
g. Grade 6

8. How many students attend your class during the current school year? If you teach several different classes, indicate the average class size. Check one.
a. Less than 10 students
b. 11-15 students
c. 16-20 students
d. 21-25 students
e. 26-30 students
f. More than 30 students

9. How would you describe the makeup of students ${ }^{5}$ in your classroom? Mark as many as necessary.
a. Regular classroom
b. Low income
c. Immigration
d. Undereducated immigration
e. Autism spectrum disorder
f. Mild intellectual impairment
g. Average intellectual disability
h. Serious learning difficulty
i. Severe learning difficulty w/dyslexia \& dysorthography
j. Severe language impairment
k. Moderate language disorder
1. Difficulty of adaptation (behaviour)

10. Do you teach? Check one.
a. Full time
b. Part time

11. What is the Index of Socio-Economic Background $\left(\mathrm{ISEB}^{6}\right)$ of the school where you teach? Enter a number from 1 to 10 (Note: 1 = most favoured school, $10=$ most disadvantaged school). If you do not know your school's ISEB, enter 0.

12. What best describe the neighbourhood where your school is located? Check one.
a. Urban (i.e. large cities)
b. Semi-urban (i.e. suburbs, small and medium municipalities)
c. Rural (i.e. villages)
d. Remote area (i.e. fishing, mining and lumber towns)

\footnotetext{
${ }^{5}$ Answers based on MÉLS classification of students with difficulties.

${ }^{6}$ The Index of socio-economic background (ISEB) is composed of two variables, the level of education of the mother and the unemployment rate of the parents, which emerged as the strongest predictors of children's academic difficulties (MELS, 2014).
} 
The following questions relate to your teaching activities carried out during the last full school year (20132014) and from September 2014 to the present (current 2014-2015 school year).

13. In your estimation, how many hours per week do you spend teaching science in your class, including astronomy? Check one.
a. I do not teach science in my class
b. Less than one hour per week
c. 1 to 2 hours per week
d. 3 to 5 hours per week
e. More than 5 hours per week

14. Is there a specialist in your school whose task is to teach science to all classrooms, including yours? Check one.
a. Yes
b. No

15. During the period described above (2013-2014 school year and from September 2014 to the present), did you teach astronomy in your class? Check one.
a. Yes (Go to question 16)
b. No (Go to question 26)

16. If you have taught astronomy in your class, was it mostly by integrating it into other subjects (i.e. French, math, arts, etc.) or separately as an autonomous subject? Check one.
a. Integrated with other subjects (Go to question 17)
b. Separately as an autonomous subject (Go to question 18)

17. With what subjects have you integrated your astronomy teaching? Mark as many as necessary.
a. French
b. English
c. Mathematics
d. Geography, history and citizenship education
e. Drama
f. Plastic arts
g. Dance
h. Music
i. Physical and Health Education
j. Ethics and Religious Culture
k. Information and communication technology

18. Among all the topics in astronomy listed below, which one have you taught to your class? Mark as many as necessary.
a. Light and shadows
b. The sun-earth-moon system
c. Solar energy
d. The earth's rotation
e. Tides
f. The solar system
g. Seasons
h. Phases of the moon and eclipses
i. Stars and galaxies (constellations)
j. Earth, atmospheric, and space technologies
k. Use of simple observation instruments (binoculars, telescopes, etc.)
1. Use of appropriate terminology, conventions, and drawings for astronomy (terrestrial globe, star chart, etc.) 
19. In your estimation, how many hours per year do you spend teaching astronomy in your classroom? Check one.
a. Less than an hour
b. 2-5 hours
c. 6-10 hours
d. 11-20 hours
e. 21-30 hours
f. More than 30 hours

20. How important are the goals and objectives listed below for the teaching of astronomy in your class? $(1=$ very important, 2 = important $3=$ not important, $4=$ not important at all).

"I teach astronomy in my class to help my students..."

\begin{tabular}{|c|c|c|c|c|c|}
\hline & Learn core knowledge in astronomy & 1 & 2 & 3 & 4 \\
\hline & Develop their competencies in astronomy and in science & 1 & 2 & 3 & 4 \\
\hline c. & Understand key concepts in astronomy & 1 & 2 & 3 & 4 \\
\hline & Develop their social skills & 1 & 2 & 3 & 4 \\
\hline & Discover the tools of astronomy & 1 & 2 & 3 & 4 \\
\hline & Develop their reading/writing skills & 1 & 2 & 3 & 4 \\
\hline & Create art productions & 1 & 2 & 3 & 4 \\
\hline & Develop their scientific attitude & 1 & 2 & 3 & 4 \\
\hline & Explore careers in astronomy & 1 & 2 & 3 & 4 \\
\hline & Discover the use and applications of astronomy in their lives & 1 & 2 & 3 & 4 \\
\hline & Develop their expertise in science & 1 & 2 & 3 & 4 \\
\hline & Understand the importance of astronomy in their lives & 1 & 2 & 3 & 4 \\
\hline
\end{tabular}

21. If you encounter difficulties in teaching astronomy in your class, what are they? Mark as many as necessary.
a. I have no difficulty teaching astronomy
b. There are not enough resources (books, demonstration equipment, astronomical instruments, etc.) available in my school
c. I don't have any experience nor training in astronomy
d. I don't have access to a suitable classroom where to do demonstrations/experiments in astronomy
e. My students show little interest about astronomy
f. I run out of time in the classroom schedule to teach astronomy
g. I lack support from the school administration, the parents' committee, etc.
h. I do not feel competent enough to teach astronomy to my students

22. Among the resources listed below, which one did you use in your teaching of astronomy? Mark as many as necessary.
a. Textbooks approved by MÉLS ${ }^{7}$
b. Books, picture books, novels, science fiction, etc.
c. Websites
d. Educational material found on the Internet (activity sheets, etc.)
e. Newspapers and magazines (print or online versions)
f. Visit to a science museum, observatory or planetarium
g. Binoculars, telescope, star finder, sundial, etc.
$\mathrm{h}$. Amateur or professional astronomer visiting my classroom
i. Television or radio show about astronomy
j. Astronomy software
k. Scale models (Earth, moon globe, scale model of the solar system, etc.)
1. Educational materials (texts, posters, PowerPoint presentations) that I have developed myself
$\mathrm{m}$. Documents from government, academic or business sources

\footnotetext{
${ }^{7}$ Ministère de l'Éducation, du Loisir et du Sport, Québec's Ministry of Education. 
23. Check the statements that best describe the room where you teach astronomy to your students. Mark as many as necessary.
a. A laboratory classroom designed for teaching science
b. A classroom with access to a laboratory
c. A classroom where I can do demonstrations or experiments using models
d. A classroom with audio-visual aids (video projector, screen, etc.)
e. A classroom offering no particular arrangement for teaching astronomy or science

24. Check the statements that best describe the equipment (telescope, binoculars, globes, models, etc.) and the resources (activity sheets, astronomy software, etc.) that you use to teach astronomy to your students. Mark as many as necessary.
a. There are plenty of equipment and resources for students and myself to use
b. The equipment we have access to is cheap, very old and in poor condition
c. There is almost no scientific equipment and resources available in my school
d. I have access to appropriate equipment for classroom demonstrations
e. I have no access to scientific equipment in my school
f. I have access to audio-visual equipment in my classroom/at my school
g. I have access to a computer room
h. I have access to astronomy software
i. Other (specify)

25. In general, how would you describe the quality of the equipment and resources available to teach astronomy in your class? Check one.
a. Excellent
b. Good
c. Fair
d. Low
e. Poor
f. I do not have access to equipment or resources for teaching astronomy

The following questions concern your own education and pre-service training in astronomy and in science.

26. How would you describe the education that you received in the following subjects as part of your pre-service training (Bachelor of Education) to become a teacher?

$(1=$ very satisfactory, 2 = satisfactory, $3=$ unsatisfactory, 4 very unsatisfactory, $5=\mathrm{I}$ have not received any training in this subject)

\begin{tabular}{|c|c|c|c|c|c|}
\hline a. Astronomy & 1 & 2 & 3 & 4 & 5 \\
\hline b. Science & 1 & 2 & 3 & 4 & 5 \\
\hline c. Science education or science teaching & 1 & 2 & 3 & 4 & 5 \\
\hline
\end{tabular}

27. In addition to your current teaching position, have you ever been employed in a scientific or technological job? Check one.
a. No
b. Yes, in a scientific library
c. Yes, in a science museum
d. Yes, in a laboratory
e. Yes, in S\&T research and development
f. Yes, in basic research in science (medicine, biology, physics, chemistry, environment)
g. Yes, in agriculture, fisheries or in mines
$\mathrm{h}$. Yes, in industry, including engineering 
28. Indicate all scientific leisure activities that you practice on a regular basis. Mark as many as necessary.
a. Read newspaper or magazine articles about science and technology
b. Read science popularization magazines
c. Read science popularization books
d. Listen to TV and radio shows about science and technology
e. Go to websites devoted to science and technology subjects
f. Visit science museums
g. Attend scientific lectures, science shows or science fairs
h. Participate in a science leisure activity (bird watching, rock collecting, sky gazing, etc.)
i. Attend science or technology debates
j. I do not practice any science leisure activity

29. Indicate all in-service training activities in astronomy teaching that you have attended since becoming a teacher. Mark as many as necessary.
a. Informal meetings with colleagues
b. Informal meetings with university researchers in science education
c. Informal meetings with amateur and/or professional astronomers or scientists
d. Workshops presented by teachers/education consultants/MÉLS representatives
e. Workshops offered by the school and/or school board
f. Workshops presented by astronomers or scientists
g. Workshops presented by academics in science education
h. Workshops/training courses online (Internet)
i. University courses in astronomy and in science
j. University courses in science education for the teaching of astronomy and science (science education)
k. Visits to other classrooms or other schools
1. I have not participated in any in-service training activity in astronomy

30. How would you describe your level of interest to participate in in-service training activities in astronomy if they were offered in the following context?

$(1=$ I would participate willingly, $2=$ I would probably participate, $3=$ I would probably not participate, $4=\mathrm{I}$ would definitely not participate, $5=$ I do not know)

\begin{tabular}{|ll|l|l|l|l|l|}
\hline a. & During school hours (with another teacher taking care of my class) & 1 & 2 & 3 & 4 & 5 \\
\hline b. & After school hours & 1 & 2 & 3 & 4 & 5 \\
\hline c. & Professional development day & 1 & 2 & 3 & 4 & 5 \\
\hline d. & Spring break & 1 & 2 & 3 & 4 & 5 \\
\hline e. & Summer vacation & 1 & 2 & 3 & 4 & 5 \\
\hline
\end{tabular}

31. How many hours of in-service training per year do you feel you need to develop, maintain or improve your astronomy teaching? Check one.
a. None
b. 3 to 5 hours per year (i.e. half-day workshop)
c. 5 to 20 hours per year (i.e. a few days of training)
d. A semester long intensive course (i.e. university course)
e. A full year without teaching (i.e. certificate or university degree)

32. How would you describe the in-service training program in astronomy offered by your school and/or school board? Check one.
a. The program is very effective
b. The program is effective
c. The program is ineffective
d. The program is very ineffective
e. There is no such program 
33. If you had the choice, would you prefer not to teach astronomy in your class? Check one.
a. Yes (Go to question 34)
b. No (Go to question 35)

34. If you would prefer not having to teach astronomy in your class, please indicate the reasons for your choice. Mark as many as necessary.

a. I do not have access to enough material and educational resources to teach astronomy

b. My initial training was inadequate for teaching astronomy

c. I have not received in-service training in astronomy since I became a teacher

d. Astronomy is of little or no interest to me

e. It is difficult to make experiments or observations in astronomy

f. I think astronomy is too complex and challenging

g. Working conditions in my classroom are difficult

h. My class has several students with learning difficulties in basic subjects (French, math)

i. I'm afraid of not being competent enough in astronomy to teach the subject well

j. I'm afraid that my students will know more than me about astronomy

$\mathrm{k}$. Astronomy is not a mandatory subject in the curriculum and there is not enough time in the class schedule for teaching astronomy

1. I prefer to concentrate my efforts on core subjects (French, math, English)

35. How did you find out about this survey? Mark as many as necessary.
a. AQEP website
b. AESTQ website
c. AQEP Facebook page
d. Vivre le primaire magazine (AQEP magazine)
e. AESTQ e-letter
f. AESTQ Facebook page
g. Email invitation
h. Email from colleagues, school, School board, others

Thank you very much for taking the time to complete this survey! 
NOTE 